\title{
¿Es posible comer rico en esta navidad y cuidar mi salud al mismo tiempo?
}

Por: Lic. Karol Castillo G

Lic. Karen Ibarra C.

Profesoras - UCIMED

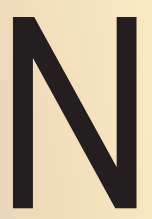

avidad es un tiempo para compartir, de unión familiar y tradiciones, pero también es una época donde los hábitos de alimentación cambian completamente, pues hay disponibilidad de preparaciones típicas de nuestra cultura como lo son los tamales, el queque navideño, el rompope, carnes, dulces, galletas, postres aderezos, dips y bebidas alcohólicas, que nos aportan grandes cantidades de energía (caloría) provenientes de grasas y azúcares principalmente, y no solo por los ingredientes que contiene, sino también porque se consumen en exceso.

Es por esto que se requiere tomar nota de algunos consejos nutricionales que nos pueden ayudar a controlar esas kilocalorías en exceso y no iniciar el año nuevo con más kilogramos de peso. Una de las principales alternativas viables que tenemos en caso de que se preparen los alimentos en nuestros hogares, es analizar las preparaciones tanto en tipo y cantidad de ingredientes requeridos, así como en el método de cocción utilizado. Lo anterior es vital para lograr con pequeños cambios, reducción de calorías sin dejar de lado el sabor y la textura de los alimentos.

Un ejemplo de lo anterior, es el queque navideño, cuyos ingredientes son frutas confitadas, licor, mantequilla, frutos secos, azúcar, huevos y harina. Una porción normal servida de este producto es de aproximadamente 100 gramos. Todos los ingredientes anteriores resultan en un producto altamente calórico proveniente de azúcar y grasas. Sin embargo, con cambios sencillos como utilizar azúcar morena con edulcorante, sustituir la grasa por puré de manzana sin azúcar, eliminar las frutas confitadas y adicionar frutas frescas como manzana picada, además

de disminuir la cantidad de huevo a la mitad, se obtienen diferencias en el aporte nutricional por porción como se indica en la siguiente tabla:

Tabla I. Comparación del valor nutricional de un queque navideño original y uno modificado.

\begin{tabular}{|c|c|c|}
\hline & $\begin{array}{l}\text { Je Navideño } \\
\text { odificación }\end{array}$ & $\begin{array}{c}\text { Queque Navideño } \\
\text { Modificado }\end{array}$ \\
\hline Energía & 579Kcal & $304 \mathrm{Kcal}$ \\
\hline Grasa Total & $31 \mathrm{~g}$ & $12 \mathrm{~g}$ \\
\hline Grasa Saturada & $4 \mathrm{~g}$ & $2 g$ \\
\hline Colesterol & $95 \mathrm{mg}$ & $20 \mathrm{mg}$ \\
\hline Carbohidratos & $57 g$ & $33 \mathrm{~g}$ \\
\hline Fibra & $1 \mathrm{~g}$ & $1 \mathrm{~g}$ \\
\hline
\end{tabular}

* Fuente: Castillo, K. Tabla composición de Alimentos INCAP

En la carrera de Nutrición de UCIMED nuestras estudiantes del curso de Laboratorio de Alimentos 2 , se dieron a la tarea de mejorar el contenido nutricional de preparaciones que se consumen en la época navideña tales como bistek a la pimienta en salsa cremosa, brownies con relleno de cheese cake , pechuga de pavo en salsa de queso y uvas, puré de camote, y galletas de jengibre. A continuación, se presenta la información de los cambios y su impacto en el aporte nutricional. 
PEGHUGA DE PAVO AHUMADA GON SALSA DE QUESO Y UVAS

\section{OBJETIVO}

Disminuir

la cantidad de grasa
INGREDIENTES CRITICOS

Mantequilla

Crema Dulce

Carne de Res
MODIFICACIÓN

Eliminar la grasa visible de la carne Cambiar mantequilla por margarina Cambiar la crema dulce por leche descremada
LOGRO

Energía disminuyó un 19\%

Grasa total disminuyó un $36 \%$

\section{BISTEK A LA PIMIENTA EN SALSA BREMOSA}

OBJETIVO

INGREDIENTES CRÍTICOS

Queso Crema

Disminuir la cantidad de grasa
Leche Evaporada Entera

\section{PURÉ DE GAMOHE}

\section{OBJETIVO}

INGREDIENTES CRIITICOS

Mantequilla
Disminuir la cantidad de grasa

\section{MODIFICACIÓN}

LOGRO

Cambiar el Queso Crema

por su versión light

Utilizar leche Evaporada

cero grasa
Grasa total disminuyó un $\mathbf{4 1 \%}$

\section{MODIFICACIÓN}

Cambiar la matequilla

por margarina light $y$

disminuir la cantidad

a la mitad

\section{LOGRO}

Grasa total disminuyo un $\mathbf{5 6} \%$

\section{BROWNES RELLENOS DE GHEESE GAKE}

\section{OBJETIVO}

Disminuir las calorias provenientes de grasa y azúcares

\section{INGREDIENTES CRÍTICOS}

Mantequilla
Azúcar
Queso Crema
Huevos

Mantequilla

Queso Crema

Huevos

\section{MODIFICACIÓN}

Sustituir la mantequilla

por puré de manzana sin azúcar

Disminuir la cantidad de de azúcar

y sustituir por edulcorante

Cambiar el queso crema por su versión light

disminuir la cantidad de huevos a la mitad

\section{GALLEAS DE JENGCHBRE}

\section{OBJETIVO}

Disminuir el contenida de grasa y azúcar y

Aumentar la Fibra

\section{INGREDIENTES CRÍTICOS}

Mantequilla

Azúcar Refinada

\section{MODIFICACIÓN}

Utilizar Edulcorante en sustitución del azúcar Cambiar la mantequilla por margarina light Utilizar la mitad de la cantidad de harina integral

\section{LOGRO}

La Energía disminuyó un $44 \%$ Grasa total disminuyó un $72 \%$ Azúcar disminuyó 16\%

\section{LOGRO}

Las Calorías se Redujeron en un $\mathbf{4 8 \%}$

Grasa total disminuyó un $\mathbf{8 0} \%$ Azucar disminuyó 47\%
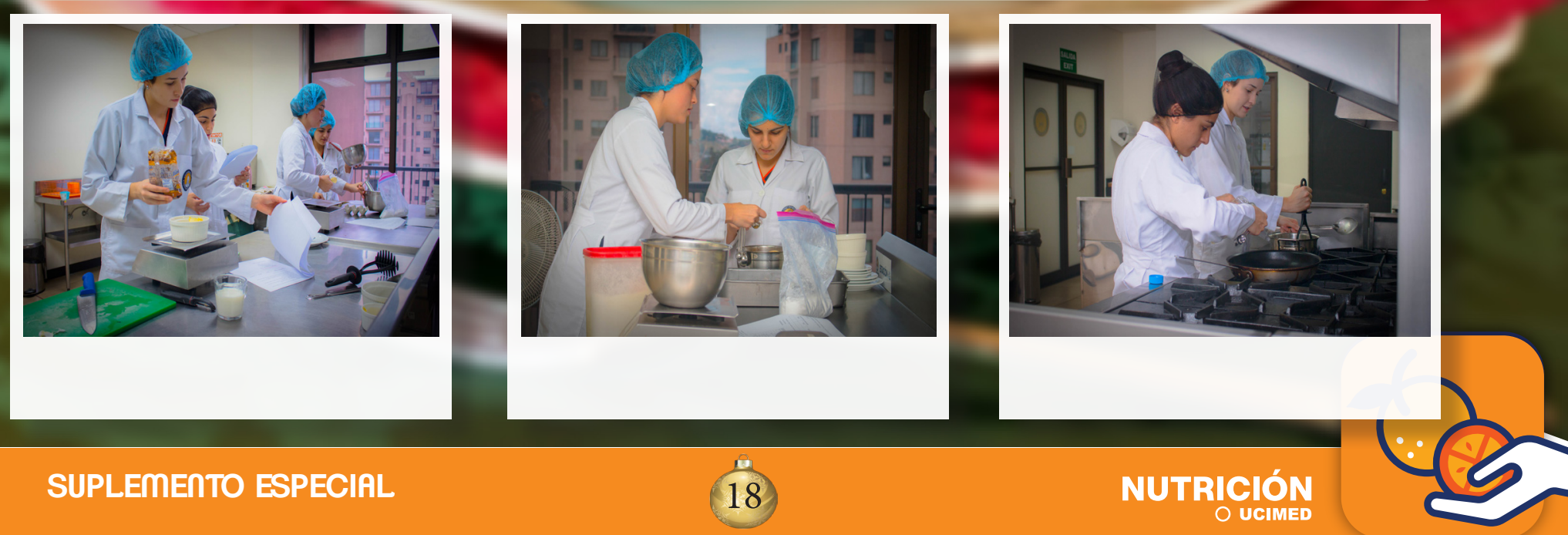